\title{
Acantholytic Squamous Cell Carcinoma of Uncommon Sites
}

\author{
Elif Eda Ozer* and Gulsen Pinar Soydemir \\ Bakirkoy Dr Sadi Konuk Research and Education Hospital, Department of Radiation Oncology, Turkey
}

*Corresponding author: Elif Eda Ozer, Bakirkoy Dr Sadi Konuk Research and Education Hospital, Department of Radiation Oncology, Turkey.

Received Date: March 28, 2019

Published Date: April 15, 2019

\begin{abstract}
Laryngeal cancers constitute $2-5 \%$ of all cancers, and $45 \%$ of all head and neck cancers. Acantholytic squamous cell carcinoma (ASCC), also known as adenoid squamous cell carcinoma, is a rarely observed histological subtype of squamous cell carcinoma (SCC). While they are rarely seen in the digestive and respiratory tracts, their course tends to be more aggressive. Furthermore, while head and neck squamous cell carcinoma tend to have a low rate of distant metastasis, the lungs are still the most common target organs involved by metastasis. Metastasis from the laryngeal region to soft tissues, skin and adrenal areas is rarely encountered.
\end{abstract}

Keywords: Acantholytic squamous cell cancer; Soft tissue metastasis

\section{Introduction}

Squamous cell cancers are the most commonly observed histopathological type of laryngeal cancer. Squamous cell cancers have verrucous, basaloid, papillary, fusiform cell, acantholytic and adenosquamous subtypes. Acantholytic squamous cell carcinoma (ASCC), also known as adenoid squamous cell carcinoma, is a rarely observed histological subtype of squamous cell carcinoma (SCC). Acantholysis develops as a result of the loss of desmosomal adhesion proteins. The loss of the cell-to-cell adhesion leads to morphological changes that mimic other cell types. It is for this reason that acantholytic SCC is mentioned in the literature with numerous different names (adenoid SCC, pseudovascular adenoid SCC, pseudoangiosarcomatous SSC, pseudoglandular SCC) [1]. O'Shea et al. [2] have demonstrated that $89 \%$ of acantholytic SCCs are associated with the loss of at least one desmosomal cell adhesion protein, while $65 \%$ are associated with the loss of two or more desmosomal protein. Desmoglein $1 / 2$ and desmoplakin are the proteins with the highest rate of loss. Acantholytic SSC is generally reported on the skin and lips that are exposed to the sun, although cases with acantholytic SCC identified in their gingiva, tongue, buccal mucosa, breasts, cecum, vulva and penis have also been reported. Although no clear estimation has been made about its prognosis due to the low number of patients, the ASCC subtype is known to have a more aggressive course [3-6]. The risk of distant metastasis in head and neck cancer patients varies between $4 \%$ and $25 \%$ [7]. The most common sites for haematogenous metastases to occur are the lungs (60\%) and bone (20\%) [8]. Lymphatic metastases, on the other hand, are observed most commonly in the mediastinal and axillary areas [9]. Metastasis from the larynx to the soft tissue and skin are seen very rarely.

\section{Discussion}

Laryngeal cancers constitute $2-5 \%$ of all cancers, and $45 \%$ of all head and neck cancers. Squamous cell carcinoma originating from the epithelium is the most common type of laryngeal cancers. There are six histologically defined subtypes of squamous cell carcinoma, which are the verrucous, basaloid, papillary, fusiform cell, acantholytic and adenosquamous subtypes. Acantholytic squamous cell carcinoma was first described by Lever in 1947 [10]. Lever initially assumed that, due to its glandular structure and epithelial proliferation, this subtype originated from the sweat glands, and hence defined these tumors as adenoacanthoma that stem from the exocrine sweat glands. Later studies showed that this subtype is actually an SCC variant of non-exocrine origin [11]. Although acantholytic squamous cell carcinoma localized to the head and neck are usually observed on the skin and lips exposed to the sun, they are also observed in the oral cavity, nasopharynx, tongue and larynx in rare cases [11-17]. The best prognosis with ASCCs has been reported by Jones et al. as being the tumors localized 
to the lips [13]. On the other hand, early metastasis and fatal disease course have been reported in cases of ASCC involving the skin [18]. Zaatari et al. reported ASCC localized to the nasopharynx in 1986 and described that ASCC with upper respiratory/digestive tract localization have a more aggressive course, as well as a poor prognosis [15]. The prognosis of ASCC localized to the mucosa, on the other hand, is subject to debate. In an article reporting nine patients with mucosal ASCC, Gozalez-Vole et al. [19] was unable to draw conclusion regarding aggressive disease course or prognosis due to the low number of patients and the differences in the tumor localization.

Follow-up data have been reported for 8 of the 12 cases with acantholytic squamous cell carcinoma with aerodigestive localization that we were able to identify in the literature [16-19]. Among these 8 cases, progression was detected in an average of 15 months, and 6 of the cases showed no response to treatment and passed away. Detailed information was provided for only one out of three patients with laryngeal acantholytic squamous cell carcinoma that we identified in literature. This patient was reported to develop recurrent disease at two months and died at nine months [20]. Tiken et al. reported a case of laryngeal cancer in whom widespread. Soft tissue and distant metastases were identified during the early postoperative period and who died of uncontrollable metastases at seven months [21]. Laryngeal cancer can spread through direct invasion, but it can metastasize to the regional lymph nodes and distant organs through haematogenous spread. The literature reports adenocarcinomas, the clear cell subtype of renal cell carcinomas, and squamous cell carcinomas as the most common histological subtypes for soft tissue metastases [20]. In a review of 118 cases with metastasis to the soft tissues, the most common soft tissue targets for metastasis were shown to be the skin (16\%), the lungs (11\%) and kidneys (10\%) [20]. Furthermore, it has been reported that among different types of head and neck tumors, the tumors of the tongue, pharynx, salivary glands and nasal cavity can also metastasize to the soft tissues (4\%). Within one month following postoperative radio chemotherapy, our patient developed soft tissue, skin and adrenal metastases that are rarely observed in laryngeal cancer. In line with the literature, the course of the disease was very aggressive, with the patient being lost within three months before receiving the planned chemotherapy. Despite the lack of clear estimation concerning the progression of acantholytic squamous cell carcinoma due to the low number of cases, it is reported that the disease has a considerably aggressive course and poor prognosis. It must be kept in mind that metastases can be detected in early periods in such cases and that the disease can even metastasize to atypical body sites.

\section{Conclusion}

Acantholytic squamous cell carcinoma is a rare variant of squamous cell carcinoma. It can especially occur on the skin and lips that are exposed to the sun. Acantholytic SSC localized outside the skin is observed more rarely. When evaluated together with the literature, it can be concluded that the acantholytic SCC has a more aggressive disease course. It must be kept in mind that metastases can be detected in early periods in such cases and that the disease can even metastasize to a typical body site.

\section{Acknowledgment}

None.

\section{Conflict of Interest}

No conflict of interest.

\section{References}

1. Mustafa Mohammad and Rebecca Wilcox (2018) Morphologic mimicry: acantholytic squamous cell carcinoma in nondermal locations-a literature review Ann. NY Acad Sci ISSN 0077-8923.

2. O'Shea C, Fitzpatrick JE, Koch PJ (2014) Desmosomal defects in acantholytic squamous cell carcinomas. J Cutan Pathol 41: 873-879.

3. Gu X, Jiang R, Fowler MR (2012) Acantholytic squamous cell carcinoma in upper aerodigestive tract: histopathology, immunohistochemical profile and epithelial mesenchymal transition phenotype change. Head Neck Pathol 6(4): 438-44.

4. Chaux A, Cubilla AL (2012) Diagnostic problems in precancerous lesions and invasive carcinomas of the penis. Semin Diagn Pathol 29(2): 72-82.

5. Zoran Jukić, Iva Ledinsky, Monika Ulamec, Mario Ledinsky, Božo Krušlin, et al. (2011) Primary acantholytic squamous cell carcinoma of the cecum: a case report. Diagnostic Pathology 6: 5

6. Horn LC, Liebert UG, Edelmann J, Höckel M, Einenkel J (2008) Adenoid squamous carcinoma (pseudoangiosarcomatous carcinoma) of the vulva: a rare but highly aggressive variant of squamous cell carcinomareport of a case and review of the literature. Int J Gynecol Pathol 27(2): 288-91.

7. de Bree R, Deurloo EE, Snow GB, Leemans CR (2000) Screening for distant metastases in patients with head and neck cancer. Laryngoscope 110: 397-401.

8. Probert JC, Thompson RW, Bagshaw MA (1974) Patterns of spread of distant metastases in head and neck cancer. Cancer 33: 127-33.

9. Spector JG, Sessions DG, Haughey BH, Chao KS, Simpson J, et al. (2001) Delayed regional metastases, distant metastases, and second primary malignancies in squamous cell carcinomas of the larynx and hypopharynx. Laryngoscope 111: 1079-1087.

10. Lever WF (1947) Adenoacanthoma of sweat glands. Carcinoma of sweat glands with glandular and epidermal elements; report of four cases. Arch Dermatol Syphilol 56: 157-171.

11. Johnson WC, Helwig EB (1966) Adenoid squamous cell carcinoma (adenoacanthoma): a clinicopathologic study of 155 patients. Cancer 19: $1639-50$.

12. Takagi M, Sakota Y, Takayama S, Ishikawa G (1977) Adenoid squamous cell carcinoma of the oral mucosa. Report of two autopsy cases. Cancer 40(5): 2250-2255.

13. Jones AC, Freedman PD, Kerpel SM (1993) Oral adenoid squamous cell carcinoma: a report of three cases and review of the literature. J Oral Maxillofac Surg 51: 676-681.

14. Zaatari GS, Santoianni RA (1986) Adenoid squamous cell carcinoma of the nasopharynx and neck region. Arch Pathol Lab Med 110: 542-546.

15. Goldman RL, Klein HZ, Sung M (1977) Adenoid squamous cell carcinoma of the oral cavity. Report of the first case arising in the tongue. Arch Otolaryngol 103: 496-498.

16. Prasad KK, Kaur S (2010) Acantholytic squamous cell carcinoma of the oral cavity: an uncommon histological variant of squamous cell carcinoma. Minerva Stomatol 59(6): 377-380.

17. Kerawala CJ (2009) Acantholytic squamous cell carcinoma of the oral cavity: a more aggressive entity. Br J Oral Maxillofac Surg 47(2): 123125. 
18. Nappi O, Pettinato G, Wick MR (1989) Adenoid (acantholytic) squamous cell carcinoma of the skin. J Cutan Pathol 16(3): 114-121.

19. González-Vela MC, Val-Bernal JF, Mayorga M, Zaldumbide L, Báscones M (2006) Adenoid squamous cell carcinoma of the larynx: an uncommon histological variant of squamous cell carcinoma. APMIS 114(6): 470473.
20. Plaza JA, Perez-Montiel D, Mayerson J, Morrison C, Suster S (2008) Metastases to soft tissue: a review of 118 cases over a 30-year period. Cancer 112(1): 193-203.

21. Tiken EE, Çolpan Öksüz D, Batur Ş, Uzel EK, Öz B, et al. (2016) Acantholytic squamous cell carcinoma of larynx as an uncommon variant of squamous cell carcinoma. Kulak Burun Bogaz Ihtis Derg 26(3): 176-180. 